P. Kulkarni MD FRCA, ${ }^{*}$ J. Webster PhD, F. Carli MD FRCA M Phil

\title{
Body heat transfer dur- ing hip surgery using active core warming
}

The purpose of this study was to evaluate the effect of core warming on heat redistribution from the core to the periphery as manifested by changes in core, mean skin temperature and mean body heat, investigated in a group of 30 patients undergoing total hip replacement. The control group $(n=10)$ had no active warming. Core warming was achieved in the humidifier group ( $n=10)$ by using humidified and warmed gases at $40^{\circ} \mathrm{C}$, whilst in the oesophageal group $(n=10)$, an oesophageal heat exchanger was used to achieve active warming. Operating room temperature and relative humidity was standardised. Aural canal and skin temperatures (15 sites) were measured before induction of anaesthesia, at the end of surgery and one hour of recovery after anaesthesia. Mean skin temperatures were calculated for a weighted four and unweighted 15 points, and mean body heat were calculated to quantify the distribution of body heat. Core temperature decreased in the control and the oesophageal groups, but not in the humidifier group at the end of surgery; by mean values $\pm S D$ of $1.9^{\circ} \mathrm{C} \pm 0.6,1.2^{\circ} \mathrm{C} \pm 0.6$ and $0.4^{\circ} \mathrm{C} \pm 0.2$, respectively $(P$ $<0.01)$. Mean skin temperature $\left(M S T_{15}\right)$ decreased in the control group by $1.0^{\circ} \mathrm{C} \pm 1.0$, but not in the actively warmed groups where the mean increased by $0.1^{\circ} \mathrm{C} \pm 1.4$ and $0.2^{\circ} \mathrm{C} \pm 0.2$ in the oesophageal and humidifier groups, respectively $(P<0.05)$. Mean body heat decreased in the control and the oesphageal groups by $350.2 \pm 155.9$ and $201 \pm 184.2$, in contrast to the humidifier group, $43.5 \pm 28.4 \mathrm{~kJ},(P<0.01)$. Thus, this study shows the effect of efficient core warming on total body heat and in ensuring adequate heat content to compensate for heat loss from the periphery.

\section{Key words}

EQUIPMENT: warming;

TEMPERATURE: body, cooling.

From the Department of Anaesthesia, Northwick Park Hospital, Watford Road, Harrow, Middlesex, U.K.

Address correspondence to: Dr. F. Carli, Department of Anaesthesia, McGill University, Royal Victoria Hospital, 687 Pine Avenue West, Room F3.01, Montreal, Que. H3A 1A1.

*Present Address: Dr. P. Kulkarni, Department of Anaesthesia, The Montreal Children's Hospital, 2300, Tupper Street, Montreal, Que. H3H 1P3.

Accepted for publication 19th March, 1995.
L'objectif de cette étude consiste à évaluer les répercussions du réchauffement central sur la distribution de la chaleur du centre vers la périphérie par la mesure des changements de la température centrale, de la température cutanée et de la chaleur corponelle moyennes. Le groupe d'étude est formé de 30 patients soumis à un remplacement total de la hanche répartis en trois groupes. Le groupe contrôle $(C ; n=10)$ ne subit pas de réchauffement actif. Le réchauffement central est réalisé dans le groupe humidificateur ( $H ; n=10)$ avec des gaz humidifiés et réchauffés à $40^{\circ} \mathrm{C}$ alors que pour le groupe oesophagien $(O ; n=10)$, on utilise un échangeur de chaleur oesophagien. La température et l'humidité relative de la salle d'opération sont standardisées. La température du conduit de l'oreille et celle de la peau (15 sites) sont mesurées avant linduction de l'anesthésie, à la fin de la chirurgie et une heure après le réveil. La tempérture cutanée moyenne est calculée avec une formule pondérée pour quatre sites et non pondérée pour 15 sites; la chaleur corporelle moyenne est calculée pour quantifier la distribution de la chaleur. La température centrale diminue à la fin de la chirurgie dans les groupes $C$ et $O$, mais non dans le groupe $H$ par (moyenne $\pm S D$ ), 1,9 $\mathrm{C} \pm 0,6$ par $1,2^{\circ} \mathrm{C} \pm 0,6$ et par $0,4^{\circ} \mathrm{C}$ $\pm 0,2$ respectivement $(P<0,01)$. La température moyenne de la peau (MST 15 ) diminue dans le groupe $C$ par 1,0 $\mathrm{C} \pm 1,0$, mais pas dans les groupes réchauffés activement où la moyenne augmente de $0,1^{\circ} \mathrm{C} \pm 1,4$ et $0,2^{\circ} \mathrm{C} \pm 0,2$ dans les groupes $O$ et $H$ respectivement $(P<0,05)$. La chaleur corporelle moyenne dans les groupes $C$ et $O$ diminue de 350,2 $\pm 155,9$ et de 201 $\pm 184,2$ comparativement au groupe $H$, de 43,5 $\pm 28,4 \mathrm{~kJ}$ $(P<0,01)$. Cette étude montre l'efficacité du réchauffement central sur la tempérture corporelle totale et l'utilité d'un apport calorique suffisant pour compenser pour la perte de chaleur périphérique.

Hypothermia is a common complication in surgical patients. The balance between heat production and heat loss determines body heat, manifest as body temperature. Anaesthesia impairs thermoregulation, increasing heat loss and suppressing heat production. After induction of anaesthesia, radiant heat loss occurs mainly from the skin by redistribution of body heat from the core. ${ }^{1}$

While measures to reduce heat loss from the skin are important in minimising perioperative hypothermia, efforts to increase heat supply to the body need to be reas- 
sessed in maintaining heat balance. Previous studies have been conducted evaluating the efficacy of humidifier and oesophageal warming devices in maintaining perioperative normothermia. ${ }^{2,3}$ However, few have assessed their effect on body heat and core and mean skin temperature changes using more then ten sites. Some concern has been raised on the interpretation of changes in body temperatures using four surface sites to calculate mean skin temperature, as it only looks at a limited number of skin sites, and this may have limitations in the anaesthetised surgical patient. ${ }^{4}$

The purpose of the study was to evaluate the effect of heat supply with two methods of active core warming on heat conservation and transfer in a group of patients undergoing hip surgery in a controlled environment.

\section{Methods}

This study received ethical committee approval and informed consent was obtained from all the subjects. Thirty patients, scheduled for elective unilateral total hip replacement (ASA I and II), apyrexic and with no underlying oesophageal diseases, were allocated randomly to three groups: a control group $(n=10)$, with no active core warming technique in the operative period; a humidifier group $(n=10)$, whose lungs were ventilated with fresh gases humidified and warmed to $40^{\circ} \mathrm{C}$ by means of a heated cascade water humidifier (Bennet), and an oesophageal group $(n=10)$ using the oesophageal heat exchanger system (Granulab, Pennco Medicals Ltd.). The demographic characteristics of the patients and the clinical data regarding duration of surgery and the ambient theatre temperatures are presented in Table I.

In the oesophageal group, the oesophageal tube was inserted after induction of anaesthesia and tracheal intubation; it was then connected to a Microtemp (ii) water heating pump (Seabrook Medical Inc.), set at $50 \mathrm{~L} \cdot \mathrm{hr}^{-1}$ to give a temperature of $40.0^{\circ} \mathrm{C}$ in the oesophageal tube, as previously described. ${ }^{3}$ Heating in the two treated groups was commenced on arrival in the operating room, before surgical incision, and terminated at the end of surgery. The temperature of the inspired gases, in the humidifier group, was measured by means of a thermocouple, near the patient end.

The patients were premedicated with papaveretum $10-15 \mathrm{mg}$ im one hour before surgery. General anaesthesia was induced with thiopentone, $3-5 \mathrm{mg} \cdot \mathrm{kg}^{-1}$, and neuromuscular blockade was achieved with vecuronium, $0.1 \mathrm{mg} \cdot \mathrm{kg}^{-1}$. The lungs were ventilated to normocapnia (Capnomac, (i) Datex) with a $66 \%$ mixture of nitrous oxide in oxygen, supplemented with an inspired concentration of $1.0 \%$ enflurane. The neuromuscular blockade was reversed at the end of surgery with neostigmine-
TABLE I Clinical data of the three groups studied (mean (range))

\begin{tabular}{|c|c|c|c|}
\hline Mean (range) & $\begin{array}{l}\text { Control } \\
n=10\end{array}$ & $\begin{array}{l}\text { Humidifier } \\
n=10\end{array}$ & $\begin{array}{l}\text { Oesophageal } \\
n=10\end{array}$ \\
\hline Age (yr) & $69(59,83)$ & $70(58,83)$ & $72(58,99)$ \\
\hline B.M.I. $\left(\mathrm{kg} \cdot \mathrm{m}^{-2}\right)$ & $23.9(18.3,33.9)$ & $26.3(22.1,31.2)$ & $28.4(23.4,32.7)$ \\
\hline $\operatorname{Sex}(M: F)$ & $4: 6$ & $5: 5$ & $3: 7$ \\
\hline $\begin{array}{l}\text { Duration of } \\
\text { surgery (min) }\end{array}$ & $114(60,170)$ & $135(90,185)$ & $109(75,145)$ \\
\hline $\begin{array}{l}\text { Ambient tem- } \\
\text { perature }\left({ }^{\circ} \mathrm{C}\right)\end{array}$ & $20.1(19.0,21.8)$ & $19.8(18.7,21.2)$ & $19.6(18.0,21.0)$ \\
\hline
\end{tabular}

atropine combination $(2.5 \mathrm{mg} / 1.2 \mathrm{mg}$ ). Blood, if required, was transfused after warming it to $37.0^{\circ} \mathrm{C}$.

Core temperature was recorded with a tympanic membrane probe (Mon-A-Therm, $\left.{ }^{(}\right)$Mallinckrodt), inserted into the aural canal under direct vision, prior to induction of anaesthesia. Core and ambient room temperatures were measured using the Mon-A-Therm 7000 100 temperature monitor. The temperature probes were calibrated against a National Physics laboratory mercury thermometer in a stirred water bath, between the temperature ranges of 25 and $40^{\circ} \mathrm{C}$ and found to be accurate to $0.1^{\circ} \mathrm{C}$.

Skin temperatures were measured at 15 sites, ${ }^{5}$ using the infra-red radiation thermometer (Minolta Cyclops 33(ii)), which has been previously evaluated. ${ }^{6}$ The 15 points were located on the forehead, cheek, neck, nipple, midarm, midforearm, dorsum of the hand, umbilicus, iliac crest, medial thigh, lateral thigh, knee, medial calf, lateral calf and the dorsum of the foot. Temperature readings were taken in all three groups of patients before induction of anaesthesia (Pre), at the end of surgery (End), but before reversal of neuromuscular blockade and one hour into recovery $(1 \mathrm{hr}$.). The operations all occurred in the same operating room, with controlled laminar airflow and relative humidity set at $40-50 \%$.

The mean skin temperature (MST) was calculated using two different formulas:

(1) Ramanathan's four-point formula, ?

$$
\begin{array}{r}
\operatorname{MST}_{4}\left({ }^{\circ} \mathrm{C}\right)=0.3 \text { (nipple temp }+ \text { arm temp) } \\
+0.2 \text { (thigh temp }+ \text { calf temp) }
\end{array}
$$

(2) Hardy and DuBois' modified fifteen-point mean unweighted formula $\left(\mathrm{MST}_{15}\right)^{5}$

$$
\mathrm{MST}_{15}\left({ }^{\circ} \mathrm{C}\right)=\left(\mathrm{T}_{1}+\mathrm{T}_{2}+\ldots+\mathrm{T}_{15}\right) / 15 \text {. }
$$

Mean body heat was calculated from the mean body temperature (MBT) using the MST $_{15}$ values, as it has been shown that accuracy of MST is greater when more than ten skin sites are used. ${ }^{8}$ 


$$
\begin{aligned}
& \mathrm{MBT}\left({ }^{\circ} \mathrm{C}\right) \\
& =(0.66 \times \text { aural canal temp. })+\left(0.34 \times \mathrm{MST}_{15}\right), \\
& \mathrm{MBH}(\mathrm{kJ})=\mathrm{MBT} \times \text { body weight }(\mathrm{kg}) \\
& \times 0.83 \text { (specific heat) } \times 4.186 .
\end{aligned}
$$

\section{Statistical analysis}

The measured core temperatures and the calculated mean skin temperatures and $\mathrm{MBH}$ at each period were grouped, and the mean values, range and standard deviation were derived for each group studied. The changes in core, mean skin temperatures and MBH were calculated at the following periods: before induction of anaesthesia (Pre) to after surgery (End), and to one hour of recovery after anaesthesia (1 hr). A two-factor (treatment and time) analysis of variance was applied. The assumptions that the residuals were normally distributed and the equality of residual variances were tested using the Shapiro Wilk's test ${ }^{9}$ and the Schweder's test, ${ }^{10}$ respectively. Treatment comparisons were made between subjects, whereas the time comparisons were made within subjects using the one way analysis of variance. Differences were considered statistically significant when $P<$ 0.05 .

\section{Results}

No complications were noted with either method of core warming. The three groups were comparable with respect to clinical data.

Mean and standard deviations of core and mean skin temperatures and calculated MBH during the three study periods are presented in the Figure. There were no differences in the basal temperatures among the three groups studied, at induction of anaesthesia. The mean, standard deviation and the range of differences in the three groups in the study period are shown in Table II.

Aural canal temperature decreased in all three groups of patients, by a mean of $1.9^{\circ} \mathrm{C}$ and $1.2^{\circ} \mathrm{C}$ in the control and the oesophageal groups, respectively; but by only $0.4^{\circ} \mathrm{C}$ in the humidifier group $(P=0.004)$. In the first hour of recovery, the control and the oesophageal groups gained more in core temperature than did the humidifier group. The mean gain values being $0.9,0.5$ and $0.3^{\circ} \mathrm{C}$ respectively $(P=0.05)$.

Mean skin temperatures (MST 15 ), during surgery, decreased by a mean of $1.0^{\circ} \mathrm{C}$ in the control group, while in the oesophageal group it decreased by only $0.1^{\circ} \mathrm{C}$. In contrast, it increased by $0.2^{\circ} \mathrm{C}$ in the humidifier group $(P=0.025)$. The values for $\mathrm{MST}_{4}$ were not different among groups, with the control decreasing $\mathrm{MST}_{4}$ by 0.7 , while in the oesophageal and the humidifier groups the $\mathrm{MST}_{4}$ increased by 0.1 and $0.2^{\circ} \mathrm{C}$, respectively $(P=\mathrm{NS})$. In the first hour in recovery, the $\mathrm{MST}_{15}$ in the control

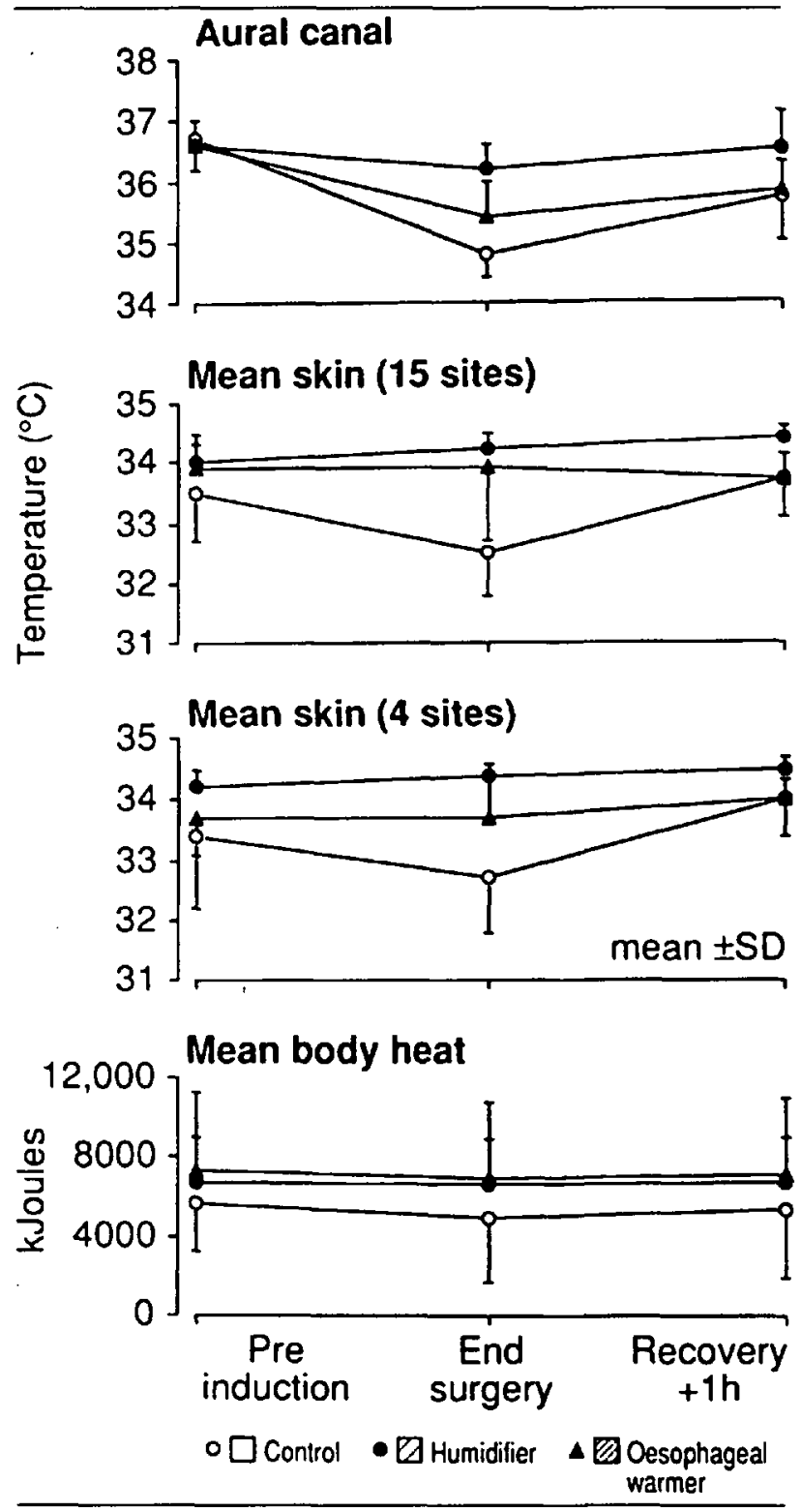

FIGURE Core and mean skin temperatures, and mean body heat values in the three groups studied during and after surgery.

and humidifier groups increased by $1.2^{\circ} \mathrm{C}$ and $0.2^{\circ} \mathrm{C}$, while in the oesophageal group $\mathrm{MST}_{15}$ decreased by $0.2^{\circ} \mathrm{C}(P=\mathrm{NS})$. In the same period $\mathrm{MST}_{4}$ increased by $1.3^{\circ}, 0.1^{\circ}$ and $0.2^{\circ} \mathrm{C}$, respectively $(P=0.015)$.

The MBH content calculated from $\mathrm{MST}_{15}$ and corrected for body weight, decreased during surgery by 350 $\mathrm{kJ}$ and $201 \mathrm{~kJ}$ in the control and the oesophageal groups, respectively, but only by $43 \mathrm{~kJ}$ in the humidifier group $(P=0.002)$. In all three groups, MBH increased in the first hour of recovery, but by $228 \mathrm{~kJ}$ in the control group and by 66 and $57 \mathrm{~kJ}$ in the oesophageal and the humidifier groups $(P=0.01)$. 
TABLE II Aural canal, mean skin temperatures and mean body heat changes (mean, SD (range)) during surgery and an hour into recovery

\begin{tabular}{|c|c|c|c|c|c|}
\hline & $\begin{array}{l}\text { Control } \\
n=10\end{array}$ & $\begin{array}{l}\text { Humidifier } \\
n=10\end{array}$ & $\begin{array}{l}\text { Oesophageal } \\
n=10\end{array}$ & $\begin{array}{l}\text { Pooled } \\
\text { SEM }\end{array}$ & $\begin{array}{l}\text { P between } \\
\text { groups }\end{array}$ \\
\hline \multicolumn{6}{|c|}{ Aural canal temp $\left({ }^{\circ} C\right)$} \\
\hline Pre-end & $1.9 \pm 0.6(1.0,3.4)$ & $0.4 \pm 0.2(0.1,0.6)$ & $1.2 \pm 0.6(0.4,2.2)$ & 0.16 & 0.004 \\
\hline $\begin{array}{l}\text { End- } 1 \mathrm{hr} \\
\text { MST } 4 \text { poi }\end{array}$ & $-0.9 \pm 0.7(-1.7,0.2)$ & $-0.3 \pm 0.5(-0.8, .60)$ & $-0.5 \pm 0.6(-1.4,0.5)$ & 0.18 & 0.054 \\
\hline Pre-end & $0.7 \pm 1.3(-1.9,2.4)$ & $-0.2 \pm 0.1(-0.4,-0.1)$ & $-0.1 \pm 0.9(-1.1,1.6)$ & 0.28 & 0.089 \\
\hline $\begin{array}{l}\text { End-1 } \mathrm{hr} \\
\text { MST } 15 \mathrm{pc}\end{array}$ & $-1.3 \pm 1.3(-2.7,0.7)$ & $-0.1 \pm 0.1(-0.4,0.02)$ & $-0.2 \pm 1.0(-2.5,0.7)$ & 0.29 & 0.015 \\
\hline Pre-end & $1.0 \pm 1.0(-1.2,2.1)$ & $-0.2 \pm 0.2(-0.4,0.3)$ & $0.1 \pm 1.4(-2.2,3.4)$ & 0.32 & 0.025 \\
\hline $\begin{array}{l}\text { End- } 1 \mathrm{hr} \\
\text { Mean bodj }\end{array}$ & $-1.2 \pm 1.0(-3.1,0.5)$ & $-0.2 \pm 0.1(-0.4,-0.1)$ & $0.2 \pm 1.1(-1.2,2.3)$ & 0.27 & 0.149 \\
\hline Pre-end & $350.2 \pm 155.9(113,674)$ & $43.5 \pm 28.4(0.9,92)$ & $201.5 \pm 184.2(-25,580.9)$ & 44.36 & 0.002 \\
\hline End-1 hr & $-228.9 \pm 159.8(-64,-488)$ & $-57.4 \pm 72.9(-173,74)$ & $-66.5 \pm 148.4(-311,95.1)$ & 41.9 & 0.01 \\
\hline
\end{tabular}

Mean \pm SD (range)

Pre $=$ before induction of anaesthesia. End $=$ end of surgery. $1 \mathrm{hr}=$ first hour of recovery. MST = mean skin temperature.

\section{Discussion}

In the present study, the humidifier group showed a demonstrable effect of core warming in terms of a minimal decrease in core temperature and $\mathrm{MBH}$, and with a small increase in MST. The oesophageal group, though showing a marked decrease in core temperature, maintained MST close to preinduction values. During the recovery period both the oesophageal and humidifier groups had very little work imposed in terms of MBH gained; this was in sharp contrast to the control group, implying that heat supply during surgery was able to enhance heat conservation. Also, while both were useful in increasing mean skin temperatures, the humidifier group was able to maintain a constant and stable MBH during the operative period.

Core warming, either with heated humidification of anaesthetic gases or by oesophageal heat transfer, have been shown to be effective in body heat conservation in surgical patients to varying extents. ${ }^{2,3,11,12}$ The reasons for the differences in effectiveness of these heating devices may be related, in part, to the duration of surgery; its effectiveness increasing with time, to the type of surgery and to the site of the recording temperature probes. In the study by Ralley $e t$ al. ${ }^{12}$ the ineffectiveness of heated humidification may have been because with an open thoracotomy there was a greater thermal debt to recover after coming off cardiopulmonary bypass and possibly to the duration of heating. The study by Stone $e t a l^{2}$ was criticised for the accuracy of core temperature measurements as they measured nasopharyngeal temperatures; the implication being that this core temperature was falsely elevated by the close proximity of the recording temperature probe to the heated inspired gases. ${ }^{13}$ The oesophageal warmer was shown to be very effective when set at a higher temperature and for a longer duration of time. ${ }^{11}$ In order to avoid these confounding factors a peripheral surgical site was studied and core temperature was measured at the tympanic membrane. The duration of surgery in the present study was not different among the various groups.

Heated humidified gases are effective as there is a large surface area available for the uptake of warm and humidified fresh gases across the tracheobronchial tree. As pointed out in an earlier study, ${ }^{3}$ the lower part of the oesophagus, where the oesophageal heating device is positioned, is less perfused and heat exchange transfer to the surrounding structures from the oesophageal warmer may be delayed. Some of the previous attempts to aid core warming did not gain favour due to potential risks associated with active humidification, such as tracheal burns, risk of infection, rupture of warming devices and risk of oesophageal damage. However, with adequate controls and precautions such as positioning of the water traps below the level of the patient, alarms for preventing overheating of humidifiers and the use of superior latex materials, these methods of core warming can be adopted in routine anaesthetic practice, especially for high risk populations such as the paediatric and geriatric age groups and those with known poor cardio-respiratory reserves. None of the patients in the present study showed any complications due to active core warming.

Anaesthesia and surgery result in heat loss and ultimately lead to perioperative body hypothermia, if steps are not taken to counter this heat loss. ${ }^{1}$ It is not yet clear the reason for thermoregulatory impairment during anaesthesia and surgery, ${ }^{14}$ but heat loss occurs mainly due to vasodilatation and cutaneous heat flux to the cooler environment with reduced heat production. ${ }^{\text {is }}$ 
Inadvertent hypothermia has been shown to have detrimental effects in various patient populations. ${ }^{16,17}$ One study demonstrated that a decrease in core temperature of only $0.8^{\circ} \mathrm{C}$ caused a much greater incidence of reduced cardiac output and increased systemic vascular resistance. ${ }^{16}$ There was also documented evidence of morbidity in terms of severe myocardial ischaemia, angina and hypoxaemia in the perioperative period, with decreases in cardiac output and increased systemic vascular resistance. These authors claimed that the likelihood of postoperative ischaemia increased by $82 \%$ for each degree Celsius decrease in temperature. ${ }^{17}$ In the present study, temperature changes of up to $1.8^{\circ} \mathrm{C}$ were observed in the control group. Though postoperative clinical outcome was not measured in this study, we believe these are considerable temperature changes which should be avoided to minimise perioperative morbidity.

Body temperature is determined by total body heat content. Body heat is unevenly distributed between a central core and a surrounding shell. This body heat distribution is in a state of constant flux, depending on the balance between heat production and loss. Thus, measuring only the skin or the core temperature may not give a fair representation of total body heat, unless taken in conjunction with $\mathrm{MBH}$ changes as an indicator of heat distribution. While heat flux transducers are suggested as an accurate means of heat transfer across the skin, mean skin temperatures can also be considered a measure of heat flux through the skin, and heat flux is related to the temperature gradient between the MST and the environmental temperature. ${ }^{18}$ By measuring the effects of heating systems on both core and mean skin temperatures, and correlating this with calculated $\mathrm{MBH}$ changes, we have attempted to analyse heat redistribution and heat transfer.

Measurement of MST was obtained using two different formulas: the weighted four-point ${ }^{7}$ and the unweighted 15-point formulas. ${ }^{5}$ Most studies quote the four-point formula which has been shown to be in close agreement with multi-site formulas in volunteer studies. ${ }^{5}$ However, it has been shown that, in surgical patients, accurate estimation of MST is obtained by measuring skin temperatures at more than ten surface points. ${ }^{8}$ The previously mentioned studies did not attempt to evaluate the distribution of body heat by measuring skin temperatures at greater than ten sites. We observed greater intraoperative temperature changes using 15 sites. This difference could be explained by the fact that calculation of $\mathrm{MST}_{4}$ did not include hand and foot temperatures, thereby excluding thermoregulatory sites of prime importance.

Thus, active core warming enhanced heat conservation resulting in considerably less requirements for heat gain during the recovery period following surgery, as manifest by smaller MBH changes in the recovery period. Efficient core warming, by increasing core temperature, facilitates body heat redistribution from the core to the periphery. The maintenance of adequate core and mean skin temperatures depends upon the effectiveness of the core warming system.

\section{References}

1 Wood MLB, Carli $F$. Inadvertent hypothermia in the operating theatre. Current Anaesthesia and Intensive Care 1991; 2: 221-31.

2 Stone DR, Downs JB, Paul WL, Perkins HM. Adult body temperature and heated humidification of anesthetic gases during general anesthesia. Anesth Analg 1981; 60: 736-41.

3 Kulkami P, Matson A, Bright J, Pearson J, Carli F. Clinical evaluation of the oesophageal heat exchanger in the prevention of perioperative hypothermia. $\mathrm{Br} \mathrm{J}$ Anaesth 1993; 70: 216-8.

4 Carli F, Ramachandra V. Human skin temperature changes during anaesthesia and surgery. Proceedings of the Physiological Society 1990; 60P.

5 Mitchell $D$, Wyndham $\mathrm{CH}$. Comparison of weighting formulas for calculating mean skin temperature. J Appl Physiol 1969; 26: 616-22.

6 Ramachandra V, Allan LG, Carli $F$. The Cyclops 33 radiation thermometer. An appraisal for use in anaesthesia. Anaesthesia 1989; 44: 328-31.

7 Ramanathan NL. A new weighting system for mean surface temperature of the human body. J Appl Physiol 1964; 19: 531-3.

8 Shanks $C A$. Mean skin temperature during anaesthesia: an assessment of formulae in the supine surgical patient. $\mathrm{Br}$ J Anaesth 1975; 47: 871-5.

9 Royston JP. An extension of Shapiro and Wilk's $W$ test for normality to large samples. Applied Statistics 1982; 31: 115-24.

10 Schweder T. A simple test for a set of sums of squares. Applied Statistics 1981; 30: 16-21.

11 Kristensen G, Guldager H, Gravensen H. Prevention of peroperative hypothermia in abdominal surgery. Acta Anaesthesiol Scand 1986; 30: 314-6.

12 Ralley FE, Ramsey JG, Wynands JE, Townsend GE, Whalley $D G$, DelliColli $P$. Effect of heated humidified gases on temperature drop after cardiopulmonary bypass. Anesth Analg 1984; 63: 1106-10.

13 Hendrickx HHL, Trahey GC, Argentieri MP. Paradoxical inhibition of decreases in body temperature by the use of heated and humidified gases (Letter). Anesth Analg 1982; 61: 393-4. 
$14 \mathrm{Hammel} \mathrm{HT}$. Anesthetics and body temperature regulation (Editorial). Anesthesiology 1988; 68: 833-5.

15 English MJM, Farmer C, Scott WAC. Heat loss in exposed volunteers. J Trauma 1990; 30: 422-5.

16 Evans JWH, Singer M, Chapple CR, Macartney N, Walker JM, Milroy EJG. Haemodynamic evidence for cardiac stress during transurethral prostatectomy. BMJ 1992; 304: 666-71.

17 Frank SM, Beattie C, Christopherson R, et al. Unintentional hypothermia is associated with postoperative myocardial ischemia. Anesthesiology 1993; 78: 468-76.

18 Sessler DI, Moayeri A. Skin surface warming: heat flux and central temperature. Anesthesiology 1990; 73: 218-24. 